\title{
Effects of extracted soy isoflavones alone on blood total and LDL cholesterol: Meta-analysis of randomized controlled trials
}

\author{
Kyoko Taku' \\ Keizo Umegaki' \\ Yoshiko Ishimi \\ Shaw Watanabe ${ }^{3}$ \\ 'Information Center, National \\ Institute of Health and Nutrition, \\ Tokyo, Japan; ${ }^{2}$ Nutritional \\ Epidemiology Program, National \\ Institute of Health and Nutrition, \\ Tokyo, Japan; ${ }^{3}$ Nutritional Education \\ Program, National Institute of Health \\ and Nutrition, Tokyo, Japan
}

\begin{abstract}
When provided concurrently with soy protein for 1-3 months, soy isoflavones exert synergistic or additive cholesterol-lowering effects. This meta-analysis was performed to evaluate the effects of extracted soy isoflavones alone (not ingested concurrently with soy protein) on total and low density lipoprotein (LDL) cholesterol. MEDLINE (1966-2007), EMBASE (1966-2007), CENTRAL (1966-2007), ICHUSHI (1983-2008), and CNKI (1979-2007) were searched for randomized placebo-controlled trials published in English, Japanese, and Chinese, describing the changes in lipid profiles in adult humans resulting from ingestion of extracted soy isoflavones for 1-3 months. Reference lists of relevant systematic reviews and meta-analyses were hand-searched. Meta-analysis of 10 and 9 trials with usable information using REVMAN found that an average of $70 \mathrm{mg}$ soy isoflavones/day (27-132 $\mathrm{mg}$, as the aglycone form) alone had a nonsignificant effect on total $(0.01 \mathrm{mmol} / \mathrm{L}[95 \% \mathrm{CI}:-0.12,0.14] ; P=0.86)$ and LDL $(0.03 \mathrm{mmol} / \mathrm{L}[95 \% \mathrm{CI}:-0.11,0.16] ; P=0.71)$ cholesterol in menopausal women, respectively. It is concluded that ingestion of about $70 \mathrm{mg}$ extracted soy isoflavones/day alone for 1-3 months does not improve total and LDL cholesterol levels in normocholesterolemic menopausal women; further studies are needed to verify the effects of extracted soy isoflavones.
\end{abstract}

Keywords: extracted soy isoflavones, lipid, total cholesterol, LDL cholesterol

\section{Introduction}

Meta-analysis of 23 randomized controlled trials (RCTs) with durations of 3-26 weeks has found that soy protein ingested with isoflavones intact significantly decreased serum levels of total cholesterol (TC) and low density lipoprotein cholesterol (LDL-C); subgroup analyses demonstrated that studies employing intakes of $>80 \mathrm{mg}$ isoflavones/day showed better effects, and that the lowering effects were most marked within 3-12 weeks (Zhan and Ho 2005). Our previous meta-analysis of 11 RCTs found that ingestion of soy protein with a high isoflavone content reduced serum LDL-C to a greater degree than ingestion of the same amount of soy protein with a low isoflavone content for 1-3 months (Taku et al 2007). These two meta-analyses suggested that soy isoflavones would have synergistic or additive effects on cholesterol lowering when provided concurrently with soy protein for 1-3 months. However, the effects of extracted soy isoflavones alone (not ingested concurrently with soy protein) are unclear.

Meta-analysis of RCTs employing isoflavones in tablet form demonstrated nonsignificant effects on TC and LDL-C; however, only 5 of the 10 studies evaluated soy-derived isoflavones (Yeung and Yu 2003). So far, only one meta-analysis of RCTs has evaluated the effects on lipid of soy isoflavones without soy protein. This included 9 trials lasting 4-26 weeks, and revealed a nonsignificant effect of extracted soy isoflavones on LDL-C, although there was a high degree of heterogeneity in mean net changes across the studies (Balk et al 2005). 
We have identified several other recently published RCTs of soy-derived isoflavones, and the present meta-analysis was performed to clarify the effects of extracted soy isoflavones ingested alone for 1-3 months on TC and LDL-C, independent of any effect of soy protein on the same parameters.

\section{Subjects and methods}

\section{Study identification and selection}

MEDLINE (1966-2007), EMBASE (1966-2007), CENTRAL (1966-2007), ICHUSHI (1983-2008), and CNKI (1979-2007) were searched for randomized placebocontrolled trials published in English, Japanese, or Chinese describing the effects of ingesting extracted soy isoflavones for 1-3 months in adult humans. Reference lists of relevant systematic reviews (Balk et al 2005; Cassidy et al 2006; Sacks et al 2006), and meta-analyses (Yeung and Yu 2003; Zhan and Ho 2006) were hand-searched.

After excluding two RCTs (Tormala et al 2006; Badeau et al 2007) that were subset analyses of an original trial (Nikander et al 2004) and two (Lissin et al 2004; Petri Nahas et al 2004) in which actual endpoint TC and LDL-C values were not clear, 12 RCTs (Nestel et al 1997; Simons et al 2000; Dewell et al 2002; Uesugi et al 2002, 2003, 2004; Nikander et al 2004; Yildiz et al 2005; Garrido et al 2006; Hall et al 2006; Cheng et al 2007; Gonzalez et al 2007) and 10 RCTs (Nestel et al 1997; Simons et al 2000; Uesugi et al 2002, 2004; Nikander et al 2004; Yildiz et al 2005; Garrido et al 2006; Hall et al 2006; Cheng et al 2007; Gonzalez et al 2007) that had respectively evaluated the effects of ingesting extracted soy isoflavones alone on TC and LDL-C in adult humans for 1-3 months, and had reported actual endpoint values for each of the comparison groups, were included in the meta-analysis. Two trials (Yildiz et al 2005; Garrido et al 2006) and one trial (Garrido et al 2006) were subsequently withdrawn, leaving 10 and 9 RCTs with usable information that were finally selected for meta-analysis of TC and LDL-C, respectively (see Figure 1). Two reviewers independently reviewed and evaluated the studies, and consensus was reached by discussion when there were disagreements.

\section{Data extraction}

Data on study design and duration, subjects, total soy isoflavones, baseline TC and LDL-C for the isoflavone group, the numbers of participants $(\mathrm{N})$ in each of the comparison groups, and the means and SDs of the endpoint TC and LDL-C values were independently extracted for metaanalysis by two reviewers with double-checking. Normally, serum cholesterol and TG concentrations are about $3 \%$ higher

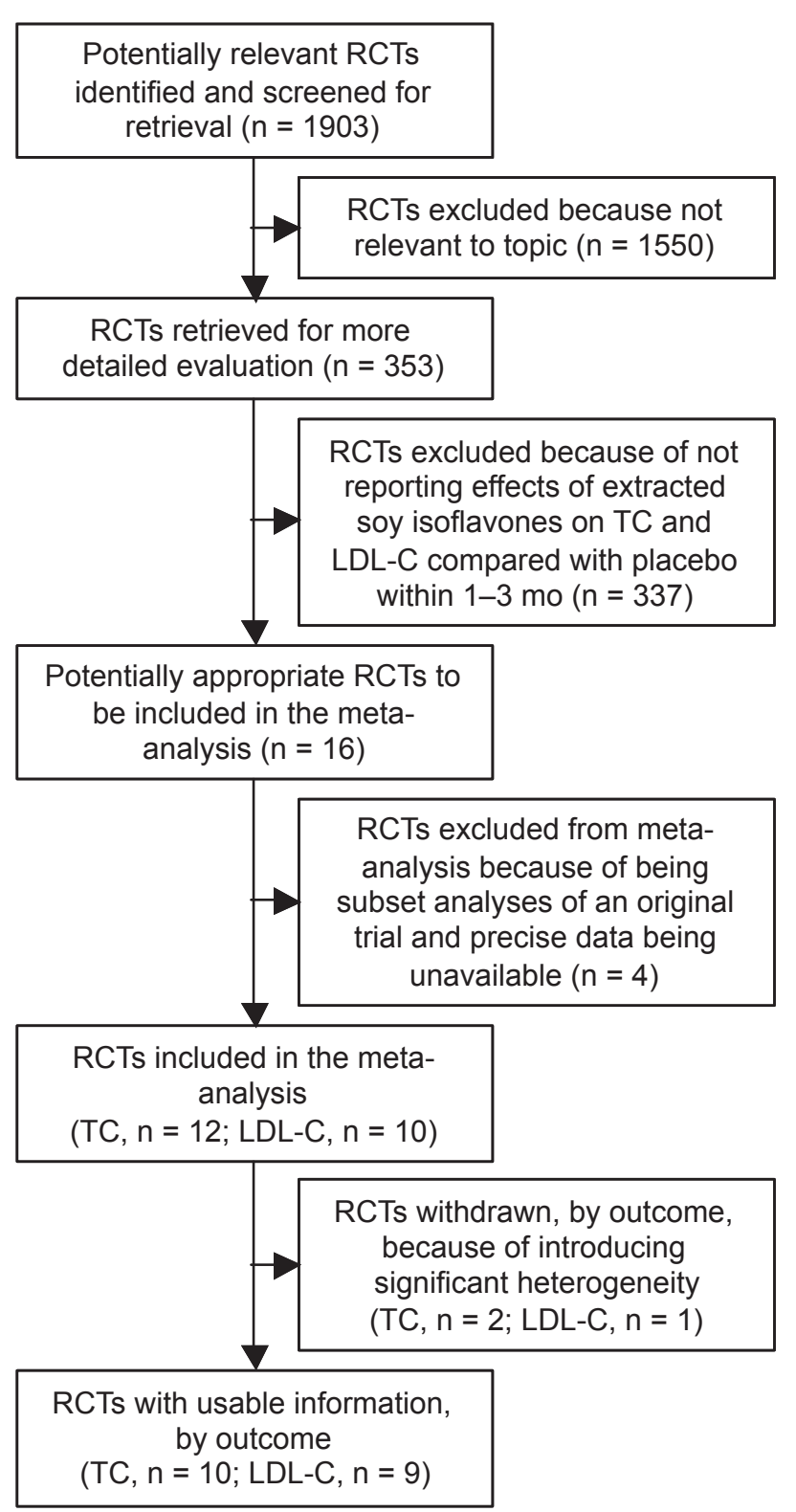

Figure I The QUOROM statement flow diagram.

Notes: Potentially relevant randomized controlled trials (RCTs) were identified from database PubMed $(n=837)$, CENTRAL $(n=386)$, EMBASE (382), ICHUSHI $(n=62)$ and CNKI $(n=236)$.

Abbreviations: QUOROM, quality of reports of meta-analyses of randomized controlled trials; RCTs, randomized controlled trials; TC, total cholesterol; LDL-C, low density lipoprotein cholesterol.

than corresponding plasma concentrations (LMC 1977), but because we were interested in mean differences in each study, we analyzed plasma and serum concentrations without correction for this difference; all results are reported as blood concentrations here.

\section{Assessment of study quality}

Sensitivity analyses on the basis of methodological quality demonstrated that poor-quality studies indicated a positive effect 
of treatment, whereas no benefit was observed in high-quality studies (Khan et al 1996). We used the Jadad scale (Jadad et al 1996) to assess the quality of RCTs included in the metaanalysis. The Jadad scale assesses randomization, blinding, and reporting of withdrawal and dropouts, and assigns studies quality scores ranging from 0 to 5 , with a score of $>2$ indicating high quality (Lind et al 2001; Sjogren and Halling 2002). Concealment of treatment allocation in RCTs was assessed as adequate, inadequate, or unclear (Schulz et al 1995).

\section{Meta-analysis}

We performed the meta-analysis to determine the combined effect of extracted soy isoflavones alone on TC and LDL-C using the weighted mean difference method in REVMAN (version 4.2.10; Cochrane Collaboration, Oxford, UK), by inputting the $\mathrm{N}$ and the means and SDs of endpoint lipid concentrations for two groups in each comparison. The treatment effect was estimated as the mean difference in endpoint values between comparison groups (ie, the value for subjects ingesting extracted soy isoflavones alone minus that for subjects ingesting a placebo). We did not use mean change from baseline outcomes instead of mean endpoint value outcomes, because mean changes were not available in most of the included studies, and imputed SDs of the changes should not be used for a majority of studies in a meta-analysis (Cochrane 2006). Although 2 of the 12 RCTs reported both endpoint values and changes (Nikander et al 2004) or percentage changes (Gonzalez et al 2007) from the baseline, we used endpoint value outcomes to maintain consistency across trials.

We used either a fixed effect model or a random effects model to calculate weighted mean differences (WMD), 95\% CIs for each comparison, a combined overall effect with $P$-value, and the $P$-value for testing heterogeneity $(P<0.1$ was considered significant). We presented the results based on the random effects model when there was heterogeneity that could not be readily explained (Zhan and Ho 2005; Cochrane 2006); otherwise, the results obtained using the fixed effect model were presented.

To explore the possible reasons for differences in results across trials, especially when the test for heterogeneity was significant $\left(P<0.1\right.$ or $I^{2}>25 \%$ ) (Cochrane 2006; Nelson et al 2006), we performed subgroup meta-analyses based on variability in the participants' baseline TC and LDL-C, intervention duration, dose of soy isoflavones, study design and study quality (Yeung and Yu 2003; Zhan and Ho 2005). Sensitivity analyses were performed on the basis of participants' baseline TC and LDL-C, dose of soy isoflavones, and study quality. We examined potential publication bias by using funnel plots of the SEs of the studies against their corresponding effect sizes.

\section{Results \\ Study and treatment group characteristics}

The characteristics of the 12 RCTs included in the metaanalysis are summarized in Table 1. Six trials used a parallel design, and the remaining trials used a crossover design. Concealment of treatment allocation for all trials was assessed as "unclear" due to insufficient information. All trials focused on menopausal women. Doses of total soy isoflavones were 42-150 mg/day (27-132 mg/day expressed as the aglycone form). One trial (Yildiz et al 2005) reported extremely small SDs for endpoint TC values, compared with SDs for other lipids in the trial and SDs reported in remaining trials. Significantly different endpoint TC and LDL-C values between the two comparison groups were reported in two trials (Yildiz et al 2005; Garrido et al 2006) and one trial (Garrido et al 2006), respectively, possibly due to their significantly different baseline values; the remaining trials did not reported significantly different TC and LDL-C values at the baseline and endpoint between comparison groups.

In addition, subjects in most of the comparisons had similar diets, with similar amounts of fat (total and saturated), cholesterol, and fiber. Most of the studies were designed to maintain subjects' usual diets and lifestyles. No significant differences in age, body weight, or body mass index were reported between the comparison groups.

Adverse events of extracted soy isoflavones were evaluated according to the evidence report (Balk et al 2005). Of the 12 RCTs included, one trial (Garrido et al 2006) that used $100 \mathrm{mg}$ soy isoflavones/day reported one case of abdominal bloating and one case of nicturia; one trial (Nikander et al 2004) using $114 \mathrm{mg}$ soy isoflavones/day reported two cases of gastralgia and one recurrence of breast cancer; one trial (Simons et al 2000) using $80 \mathrm{mg}$ soy isoflavones/day reported one case of paresthesia and one case of brief menstrual period 5 weeks into the treatment (the subject being $>2$ years postmenopausal).

\section{Meta-analysis}

Meta-analysis of the $12 \mathrm{RCTs}$ that reported the endpoint TC demonstrated significant heterogeneity $(P<0.00001)$. Use of the random effects model did not reveal any significant effect of extracted soy isoflavones alone on TC. Excluding two outlying trials (Yildiz et al 2005; Garrido et al 2006) 
Table I Characteristics of 10 included randomized placebo-controlled trials with usable information

\begin{tabular}{|c|c|c|c|c|c|c|}
\hline \multirow{2}{*}{$\begin{array}{l}\text { Study and } \\
\text { reference }\end{array}$} & \multirow{2}{*}{$\begin{array}{l}\text { Design and } \\
\text { duration }^{a}\end{array}$} & \multirow[t]{2}{*}{ Subjects $^{\mathrm{b}}$} & \multirow{2}{*}{$\begin{array}{l}\text { Total soy isoflavones } \\
(\mathrm{mg} / \mathrm{d})^{c}\end{array}$} & \multirow{2}{*}{$\begin{array}{l}\text { Jadad } \\
\text { scale }\end{array}$} & \multicolumn{2}{|c|}{ Baseline lipids $^{d}$} \\
\hline & & & & & $\mathrm{TC}$ & LDL-C \\
\hline Cheng et al 2007 & $\begin{array}{l}\mathrm{P} ; \mathrm{R}+; \mathrm{DB}+\mathrm{WD} \\
(\mathrm{I} \%) ; 3 \mathrm{mo}\end{array}$ & 60 healthy PoW & $\begin{array}{l}60 \text { [37 (De, } 41 \% ; \mathrm{Ge}, 52 \% ; \\
\text { Gle, } 7 \%)]\end{array}$ & 5 & 5.70 & 3.10 \\
\hline Dewell et al 2002 & $\begin{array}{l}\mathrm{P} ; \mathrm{R} ; \mathrm{DB} ; \mathrm{WD} \\
(0 \%) ; 2 \mathrm{mo}\end{array}$ & 36 PoW & $\begin{array}{l}\text { I } 50 \text { (Ge, } 27 \% \text {; De and Gle, } 33 \% \text {; } \\
\text { glycosides, } 40 \% \text { ) [128] }\end{array}$ & 3 & 6.80 & NR \\
\hline Garrido et al 2006 & $P ; R ; D B+; 12 w k$ & 29 healthy PoW & [95 (De, 49\%; Ge, 5I\%)] & 3 & $5.50^{*}$ & $3.40^{*}$ \\
\hline $\begin{array}{l}\text { Gonzalez et al } \\
2007\end{array}$ & $\begin{array}{l}\text { CO; R+; DB+; } \\
\text { WD (I9\%); I2 wk }\end{array}$ & 32 type 2 diabetes PoW & $\begin{array}{l}\text { [1 } 32 \text { (De, 37\%; Ge, 53\%; } \\
\text { Gle, I0\%)] }\end{array}$ & 5 & 5.40 & 3.40 \\
\hline Hall et al 2006 & $\begin{array}{l}C O ; R ; D B+W D \\
(12 \%) ; 8 w k\end{array}$ & II7 healthy PoW & [50 (De, 33\%; Ge, 67\%)] & 4 & 6.03 & 3.88 \\
\hline Nestel et al 1997 & $\begin{array}{l}\text { CO; R; SB;WD } \\
(9 \%) ; 5 \text { wk }\end{array}$ & $23 \mathrm{MPW}$ & $\begin{array}{l}{[80 \text { (De, } 42 \% ; \mathrm{Ge}, 54 \% ;} \\
\mathrm{Gle}, 4 \%)]\end{array}$ & 2 & 5.54 & 3.57 \\
\hline Nikander et al 2004 & $\begin{array}{l}\mathrm{CO} ; \mathrm{R}+; \mathrm{DB}+ \\
\text { WD (I0\%); } 3 \text { mo }\end{array}$ & $\begin{array}{l}62 \text { PoW with a history } \\
\text { of breast cancer }\end{array}$ & $\begin{array}{l}\text { [I I } 4 \text { (De, 36\%; Ge, 6\%; } \\
\text { Gle, 58\%)] }\end{array}$ & 5 & 5.88 & 3.87 \\
\hline Simons et al 2000 & $\begin{array}{l}\mathrm{CO} ; \mathrm{R} ; \mathrm{DB}+\mathrm{WD} \\
(\mathrm{I} \%) ; 8 \mathrm{wk}\end{array}$ & 23 healthy PoW & [80 (De and $\mathrm{Ge}, 100 \%)]$ & 4 & 5.86 & 3.94 \\
\hline Uesugi et al 2002 & $\begin{array}{l}\mathrm{P} ; \mathrm{R} ; \mathrm{DB} ; \mathrm{WD} \\
(0 \%) ; 4 \mathrm{wk}\end{array}$ & 23 healthy PW & $\begin{array}{l}62 \text { [38 (De, 52\%; Ge, II\%; } \\
\text { Gle, 37\%)] }\end{array}$ & 3 & 5.85 & 3.83 \\
\hline Uesugi et al 2003 & $\begin{array}{l}\mathrm{P} ; \mathrm{R} ; \mathrm{WD}(4 \%) \\
3 \text { mo }\end{array}$ & 22 PoW & $\begin{array}{l}62 \text { [38 (De, 52\%; Ge, II\%; } \\
\text { Gle, 37\%)] }\end{array}$ & 2 & 5.79 & NR \\
\hline Uesugi et al 2004 & $\mathrm{CO} ; \mathrm{R} ; \mathrm{DB}+; 4 \mathrm{wk}$ & $58 \mathrm{CW}$ & $\begin{array}{l}42 \text { [27 (De, } 46 \% ; \mathrm{Ge}, 13 \% \\
\text { Gle, } 41 \%)]\end{array}$ & 3 & 5.87 & 3.62 \\
\hline Yildiz et al 2005 & $\begin{array}{l}\mathrm{P} ; \mathrm{R} ; \mathrm{SB} ; \mathrm{WD}(0 \%) \\
3 \mathrm{mo}\end{array}$ & 80 healthy PoW & {$[40 \mathrm{mg} / \mathrm{d}(\mathrm{Ge}, 100 \%)]$} & 2 & $5.81^{*}$ & 3.98 \\
\hline
\end{tabular}

Notes: ${ }^{a}$, Parallel; CO, crossover; R, randomized; R+, randomized by appropriate method; DB, double-blinded; DB+, double-blinded by appropriate method; SB, single-blinded; WD, withdrawals and dropouts described. ' ${ }^{\circ}$ Number randomized; PoW, postmenopausal women; MPW, menopausal and perimenopausal women; PW, perimenopausal women; CW, climacteric women. ' $V$ alues in brackets are expressed as the aglycone form; De, daidzein; Ge, genistein; Gle, glycitein. ${ }^{\mathrm{d}}$ Total cholesterol (TC) and LDL cholesterol (LDL-C) concentration (mmol/L) for soy isoflavones treatment group; to convert $\mathrm{mg} / \mathrm{dL}$ to $\mathrm{mmol} / \mathrm{L}$, multiply by $0.02586 ;{ }^{*} P<0.05$ vs. placebo.

showing the poorest overlap (apparently due to the extremely small SDs and significant difference in baseline values) on the forest plot, meta-analysis of 10 RCTs with usable information (see Figure 1) using the fixed effect model demonstrated nonsignificant heterogeneity and a nonsignificant effect of an average intake of 73 (27-132, as the aglycone form) $\mathrm{mg}$ soy isoflavones/day on TC $(0.01 \mathrm{mmol} / \mathrm{L}$ [95\% CI: -0.12 , 0.14]; $P=0.86$ ). Results obtained using the random effects model were identical.

Meta-analysis of the 10 RCTs that reported the endpoint LDL-C demonstrated significant heterogeneity $(P=0.003)$, and use of the random effects model revealed no significant effect of extracted soy isoflavones alone on LDL-C. Excluding one outlying trial (Garrido et al 2006) with the poorest overlap (apparently due to the significant difference in baseline values) on the forest plot, meta-analysis of 9 RCTs with usable information (see Figure 1) demonstrated nonsignificant heterogeneity and a nonsignificant effect of an average intake of 67 (27-132, as the aglycone form) $\mathrm{mg}$ soy isoflavones/day using the fixed effect model (see Figure 2$)$ on LDL-C $(0.03 \mathrm{mmol} / \mathrm{L}$ [95\% CI: -0.11 , $0.16] ; P=0.71)$. Results obtained using the random effects model were similar.

Subgroup analyses for the effect on LDL-C found that trials lasting $>2$ months resulted in significant heterogeneity and that trials with a parallel design resulted in a significant effect (see Table 2). Subgroup analyses for the effect on TC on the basis of the same variables did not reveal any subgroups with significant results. Sensitivity analyses excluding one trial with LDL-C $\leq 3.36 \mathrm{mmol} / \mathrm{L}$ (Cheng et al 2007) or one trial with $\mathrm{TC}>6.21 \mathrm{mmol} / \mathrm{L}$ (Dewell et al 202), trials that evaluated $20-40$ (or $>80$ ) $\mathrm{mg}$ soy isoflavone aglycones/day, or trials of poor quality did not significantly influence the results. The funnel plots for the effects on TC and LDL-C did not indicate any obvious publication bias (data not shown). 


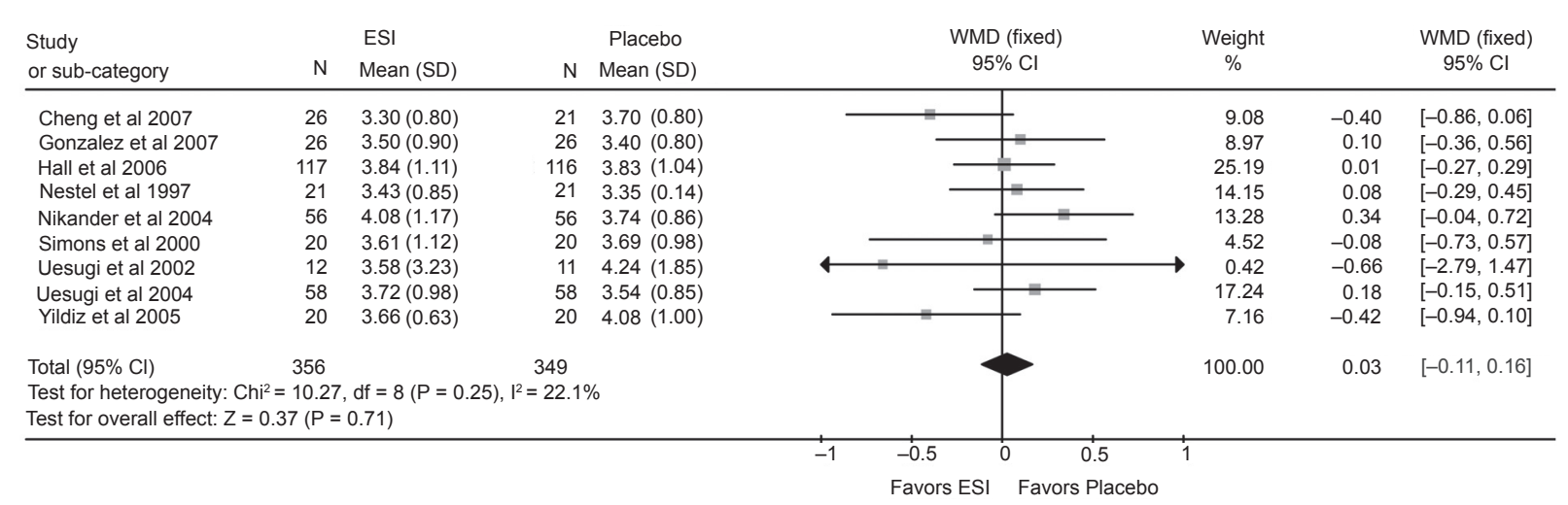

Figure 2 Effect of extracted soy isoflavones (ESI) alone on blood LDL cholesterol.

Notes: Weight assigned by REVMAN software based on N and SD.WMD, Weighted mean difference in endpoint values between the ESI alone (not ingested concurrently with soy protein) and placebo groups; fixed, fixed effect model. Horizontal lines denote the $95 \% \mathrm{Cl}$. $\mathbf{\boldsymbol { a }}$, point estimate (size of the square corresponds to its weight); $\bullet$, combined overall effect of ESI treatment.

\section{Discussion}

Although two previous meta-analyses have suggested that soy isoflavones have synergistic or additive effects in lowering TC and LDL-C when provided concurrently with soy protein for 1-3 months, especially in hypercholesterolemic $(\mathrm{TC}>6.21 \mathrm{mmol} / \mathrm{L}$ or LDL-C $>4.14 \mathrm{mmol} / \mathrm{L})$ subjects
(Zhan and Ho 2005; Taku et al 2007), the present metaanalysis found that ingestion of an average of $70 \mathrm{mg}$ extracted soy isoflavones/day (as the aglycone form) alone (not ingested concurrently with soy protein) for 1-3 months did not significantly change TC and LDL-C compared with placebo in normocholesterolemic menopausal women. The

Table 2 Combined treatment effect of extracted soy isoflavones alone on LDL cholesterol in subgroup analyses

\begin{tabular}{|c|c|c|c|c|c|}
\hline Variables & $\begin{array}{l}\text { No. of } \\
\text { trials }\end{array}$ & $\begin{array}{l}\text { Sample size } \\
\text { (ESI/PLA) }\end{array}$ & $\begin{array}{l}\text { WMD (95\% Cl) } \\
(\mathrm{mmol} / \mathrm{L})\end{array}$ & $P$ for effect & $\begin{array}{l}P \text { for } \\
\text { heterogeneity }\end{array}$ \\
\hline \multicolumn{6}{|c|}{ Baseline LDL cholesterol } \\
\hline$\leq 3.36 \mathrm{mmol} / \mathrm{L}$ & 1 & $26 / 21$ & $-0.04(-0.86,0.06)$ & 0.09 & Not available \\
\hline$>3.36 \mathrm{mmol} / \mathrm{L}$ & 8 & $330 / 328$ & $0.07(-0.08,0.2 \mathrm{I})$ & 0.35 & 0.47 \\
\hline \multicolumn{6}{|l|}{ Study duration } \\
\hline$\leq 2 \mathrm{mo}$ & 5 & $228 / 226$ & $0.06(-0.11,0.24)$ & 0.49 & 0.87 \\
\hline$>2 \mathrm{mo}$ & 4 & $128 / 123$ & $-0.07(-0.46,0.31)$ & 0.70 & 0.04 \\
\hline \multicolumn{6}{|c|}{ Total isoflavone aglycones } \\
\hline $20-40 \mathrm{mg} / \mathrm{d}$ & 4 & $116 / 110$ & $-0.11(-0.35,0.13)$ & 0.35 & 0.11 \\
\hline $41-80 \mathrm{mg} / \mathrm{d}$ & 3 & $158 / 157$ & $0.02(-0.19,0.23)$ & 0.83 & 0.91 \\
\hline$>80 \mathrm{mg} / \mathrm{d}$ & 2 & $82 / 82$ & $0.24(-0.05,0.54)$ & 0.10 & 0.43 \\
\hline \multicolumn{6}{|c|}{ Daidzein and genistein } \\
\hline $20-40 \mathrm{mg} / \mathrm{d}$ & 4 & $116 / 110$ & $-0.11(-0.350 .13)$ & 0.35 & 0.11 \\
\hline $4 \mathrm{I}-80 \mathrm{mg} / \mathrm{d}$ & 4 & $214 / 213$ & $0.10(-0.09,0.28)$ & 0.30 & 0.52 \\
\hline$>80 \mathrm{mg} / \mathrm{d}$ & I & $26 / 26$ & $0.10(-0.36,0.56)$ & 0.67 & Not available \\
\hline \multicolumn{6}{|l|}{ Study design } \\
\hline Parallel & 3 & $58 / 52$ & $-0.42(-0.75,0.08)$ & 0.02 & 0.97 \\
\hline Crossover & 6 & $298 / 297$ & $0.11(-0.04,0.27)$ & 0.14 & 0.79 \\
\hline \multicolumn{6}{|l|}{ Study quality } \\
\hline High & 7 & $315 / 308$ & $0.06(-0.10,0.21)$ & 0.47 & 0.30 \\
\hline Poor & 2 & $4|/ 4|$ & $-0.09(-0.39,0.21)$ & 0.57 & 0.12 \\
\hline
\end{tabular}

Abbreviations: WMD, weighted mean difference; ESI, extracted soy isoflavones; PLA, placebo. 
inconsistency of the results might be due mainly to the differences in effects between extracted soy isoflavones alone and soy isoflavones provided concurrently with soy protein. Another explanation might be that the two previous metaanalyses included more trials evaluating the effects of soy protein using larger amounts of soy-associated isoflavones in hypercholesterolemic subjects and used different approaches to determine the combined treatment effects. The lack of any beneficial effects of extracted soy isoflavones alone on TC and LDL-C was consistent with a previous meta-analysis that evaluated RCTs of soy isoflavones without soy protein (Balk et al 2005). However, that study noted a high degree of heterogeneity with mean net changes across the 9 included trials with durations of 4-26 weeks using the inverse variance method and by arbitrarily assuming the correlation coefficient between baseline and endpoint lipid values to be 0.5 .

A large cohort study reported that high isoflavone intake from soy foods was associated with a reduced risk of cerebral and myocardial infarction in Japanese women, the risk reduction being pronounced for postmenopausal women (Kokubo et al 2007). It is still unclear why intake of isoflavones as a component of intact soy protein or soy foods had beneficial effects on lipid profile, whereas extracted soy isoflavones alone had no such effects. When producing the soy isoflavone extract, alcohol extraction may have removed the active agent, the isoflavones may have been inactivated during the process of purification, or some enabling factor in soy protein may be required for the beneficial effects of soy isoflavones on lipid profiles (Clarkson and Anthony 1998). The beneficial effects of soy protein might require synergistic interaction between isoflavones and other soy components (Clarkson 2002). Isoflavone glycosides are not absorbed intact across the enterocytes of healthy adults, and their bioavailability requires initial hydrolysis by intestinal $\beta$-glucosidases for uptake to the peripheral circulation (Setchell et al 2002). Absorption of isoflavones is affected by food matrix and processing in humans (de Pascual-Teresa et al 2006), and differences in bioavailability between soy isoflavones contained in intact soy protein and in various extract supplements (without soy protein) may account for the differences in effects on lipid profiles.

Subgroup and sensitivity analyses based on participants' baseline lipid values, soy isoflavone dose, and study quality revealed no significant influence of extracted soy isoflavones on TC and LDL-C. However, interpretation of the results for any of the variables considered is limited because of the small number of trials available. We did not conduct subgroup analysis to evaluate the effect of isoflavone metabolites (equol and O-DMA) because only one trial had reported that being an equol producer or nonproducer was not a factor influencing the effects of extracted soy isoflavones on lipid profiles (Nikander et al 2004); another trial reported the urinary excretion of equol and O-DMA for equol producers and nonproducers, but did not address the effect on lipids.

In conclusion, our meta-analysis has shown that ingestion of about $70 \mathrm{mg}$ extracted soy isoflavones/day (as the aglycone form) alone (not ingested concurrently with soy protein) for 1-3 months does not decrease blood TC and LDL-C levels in normocholesterolemic menopausal women. Further studies are needed to verify the long-term effects of extracted soy isoflavones alone in other subjects and possible adverse events.

\section{Acknowledgments}

This study was supported partially by a grant from the Fuji Foundation for Protein Research, Osaka, Japan. KT contributed to the study search and selection, data extraction, metaanalysis, and preparation of the manuscript, KU confirmed the study selection and extracted data, and YI and SW contributed to the final version of the manuscript. None of the authors had any financial or personal conflicts of interest.

\section{References}

Badeau R, Jauhiainen M, Metso J, et al. 2007. Effect of isolated isoflavone supplementation on ABCA1-dependent cholesterol efflux potential in postmenopausal women. Menopause, 14:293-9.

Balk E, Chung M, Chew P, et al. 2005. Effects of soy on health outcomes: Evidence report/Technology assessment No. 126. Rockville, MD: Agency for Healthcare Research and Quality.

Cassidy A, Albertazzi P, Lise Nielsen I, et al. 2006. Critical review of health effects of soyabean phyto-oestrogens in post-menopausal women. Proc Nutr Soc, 65:76-92.

Cheng G, Wilczek B, Warner M, et al. 2007. Isoflavone treatment for acute menopausal symptoms. Menopause, 14:468-73.

Clarkson TB, Anthony MS. 1998. Phytoestrogens and coronary heart disease. Baillieres Clin Endocrinol Metab, 12:589-604.

Clarkson TB. 2002. Soy, soy phytoestrogens and cardiovascular disease. $J$ Nutr, 132:566S-9S.

Cochrane Collaboration. 2006. Cochrane Handbook for Systematic Reviews of Interventions Version 4.2.6. Accessed on March 10, 2008. URL: http:// www.cochrane.org/resources/handbook/Handbook4.2.6Sep2006.pdf.

de Pascual-Teresa S, Hallund J, Talbot D, et al. 2006. Absorption of isoflavones in humans: effects of food matrix and processing. J Nutr Biochem, 17:257-64.

Dewell A, Hollenbeck CB, Bruce B. 2002. The effects of soy-derived phytoestrogens on serum lipids and lipoproteins in moderately hypercholesterolemic postmenopausal women. J Clin Endocrinol Metab, $87: 118-21$.

Garrido A, De la Maza MP, Hirsch S, et al. 2006. Soy isoflavones affect platelet thromboxane A2 receptor density but not plasma lipids in menopausal women. Maturitas, 54:270-6.

Gonzalez S, Jayagopal V, Kilpatrick ES, et al. 2007. Effects of isoflavone dietary supplementation on cardiovascular risk factors in type 2 diabetes. Diabetes Care, 30:1871-3.

Hall WL, Vafeiadou K, Hallund J, et al. 2006. Soy-isoflavone-enriched foods and markers of lipid and glucose metabolism in postmenopausal women: interactions with genotype and equol production. Am J Clin Nutr, 83:592-600. 
Jadad AR, Moore RA, Carroll D, et al. 1996. Assessing the quality of reports of randomized clinical trials: is blinding necessary? Control Clin Trials, 17:1-12.

Khan KS, Daya S, Jadad A. 1996. The importance of quality of primary studies in producing unbiased systematic reviews. Arch Intern Med, 156:661-6.

Kokubo Y, Iso H, Ishihara J, et al. 2007. Association of dietary intake of soy, beans, and isoflavones with risk of cerebral and myocardial infarctions in Japanese populations: the Japan Public Health Center-based (JPHC) study cohort I. Circulation, 116:2553-62.

Linde K, Jonas WB, Melchart D, et al. 2001. The methodological quality of randomized controlled trials of homeopathy, herbal medicines and acupuncture. Int J Epidemiol, 30:526-31.

Lissin LW, Oka R, Lakshmi S, et al. 2004. Isoflavones improve vascular reactivity in post-menopausal women with hypercholesterolemia. Vasc Med, 9:26-30.

[LMC] Laboratory Methods Committee of the Lipid Research Clinics Program of the National Heart, Lung, and Blood Institute. 1977. Cholesterol and triglyceride concentrations in serum/plasma pairs. Clin Chem, 23:60-3.

Nelson HD, Vesco KK, Haney E, et al. 2006. Nonhormonal therapies for menopausal hot flashes: systematic review and meta-analysis. JAMA, 295:2057-71.

Nestel PJ, Yamashita T, Sasahara T, et al. 1997. Soy isoflavones improve systemic arterial compliance but not plasma lipids in menopausal and perimenopausal women. Arterioscler Thromb Vasc Biol, 17:3392-8.

Nikander E, Tiitinen A, Laitinen K, et al. 2004. Effects of isolated isoflavonoids on lipids, lipoproteins, insulin sensitivity, and ghrelin in postmenopausal women. J Clin Endocrinol Metab, 89:3567-72.

Petri Nahas E, Nahas Neto J, De Luca L, et al. 2004. Benefits of soy germ isoflavones in postmenopausal women with contraindication for conventional hormone replacement therapy. Maturitas, 48:372-80.

Sacks FM, Lichtenstein A, Van Horn L, et al. 2006. Soy protein, isoflavones, and cardiovascular health: an American Heart Association Science Advisory for professionals from the Nutrition Committee. Circulation, 113:1034-44.
Schulz KF, Chalmers I, Hayes RJ, et al. 1995. Empirical evidence of bias. Dimensions of methodological quality associated with estimates of treatment effects in controlled trials. JAMA, 273:408-12.

Setchell KD, Brown NM, Zimmer-Nechemias L, et al. 2002. Evidence for lack of absorption of soy isoflavone glycosides in humans, supporting the crucial role of intestinal metabolism for bioavailability. Am J Clin Nutr, 76:447-53.

Simons LA, von Konigsmark M, Simons J, et al. 2000. Phytoestrogens do not influence lipoprotein levels or endothelial function in healthy, postmenopausal women. Am J Cardiol, 85:1297-301.

Sjogren P, Halling A. 2002. Quality of reporting randomised clinical trials in dental and medical research. Br Dent J, 192:100-3.

Taku K, Umegaki K, Sato Y, et al. 2007. Soy isoflavones lower serum total and LDL cholesterol in humans: a meta-analysis of 11 randomized controlled trials. Am J Clin Nutr, 85:1148-56.

Tormala RM, Nikander E, Tiitinen A, et al. 2006. Serum cholesterol efflux potential in postmenopausal women treated with isolated isoflavones. Menopause, 13:96-101.

Uesugi S, Watanabe S, Ishiwata N, et al. 2004. Effects of isoflavone supplements on bone metabolic markers and climacteric symptoms in Japanese women. Biofactors, 22:221-8.

Uesugi T, Fukui Y, Yamori Y. 2002. Beneficial effects of soybean isoflavone supplementation on bone metabolism and serum lipids in postmenopausal japanese women: a four-week study. J Am Coll Nutr, 21:97-102.

Uesugi T, Toda T, Okuhira T, et al. 2003. Evidence of estrogenic effect by the three-month-intervention of isoflavone on vaginal maturation and bone metabolism in early postmenopausal women. Endocr J, 50:613-19.

Yeung J, Yu TF. 2003. Effects of isoflavones (soy phyto-estrogens) on serum lipids: a meta-analysis of randomized controlled trials. Nutr J, 2:15.

Yildiz MF, Kumru S, Godekmerdan A, et al. 2005. Effects of raloxifene, hormone therapy, and soy isoflavone on serum high-sensitive C-reactive protein in postmenopausal women. Int J Gynaecol Obstet, 90:128-33.

Zhan S, Ho SC. 2005. Meta-analysis of the effects of soy protein containing isoflavones on the lipid profile. Am J Clin Nutr, 81:397-408. 
